REVISTA DE DERECHO UNED, NÚM. 24, 2019

\title{
LA INESTABILIDAD ECONÓMICA Y FINANCIERA EN EL ÁMBITO DE LA SEGURIDAD NACIONAL
}

\author{
ECONOMIC AND FINANCIAL INSTABILITY \\ IN THE FIELD OF NATIONAL SECURITY
}

Rafael GálVEz Bravo

Doctorando en Derecho y Ciencias Sociales UNED

Resumen: La economía es un elemento fundamental en nuestras vidas; independientemente del conocimiento académico que tengamos de ella, todo el mundo tiene conocimientos básicos sobre la misma para manejarnos en nuestra vida cotidiana. A pesar de ser un tema del que todos podemos hablar, es una gran desconocida puesto que hasta los más expertos en la materia no han podido pronosticar la crisis de la última década (y eso que es un hecho constatado que la economía se mueve por ciclos).

La economía es un factor clave para la Seguridad Nacional y consiguientemente para los Servicios de Inteligencia del Estado, aunque debe incluirse dentro de esta responsabilidad a todos los agentes económicos, públicos y privados; de esta manera se puede confirmar el dicho que «la unión hace la fuerza».

Palabras clave: Seguridad nacional, inestabilidad económica y financiera, seguridad económica, inteligencia económica, Estrategias de Seguridad Nacional, riesgos y amenazas.

Abstract: The economy is a fundamental element in our lives; regardless of the academic knowledge we have of it, everyone has basic knowledge on this fact to manage in our daily lives. Despite being an issue that we can all talk about, it is a great unknown because even the most experts in the field have not been able to predict the crisis of the last decade (and that is a fact that the economy moves through cycles). 
The economy is a fundamental factor for national security and consequently for state intelligence services, although all economic, public and private actors must be included within this responsibility; in this way one can confirm the saying that «the union makes the force».

Keywords: Homeland security, economic and financial instability, economic security, economic intelligence, Security Strategies, risks and threats.

Recepción original: 10/12/2018

Aceptación original: 09/04/2019

Sumario: I. Contexto histórico. II. Contexto actual. III. La inestabilidad económica y financiera. III.a. Conceptos generales. III.b. Causas de la inestabilidad económica y financiera. III.c. Líneas de acción estratégica. III.d. Potenciadores de riesgo. III.e. Responsabilidades respecto de la Seguridad Nacional. III.e.i. Respuesta a las amenazas a la Seguridad Nacional. 1. III.e.i.1. Inteligencia. III.e.i.2. Respuesta penal. III.e.ii. Operadores responsables en la Seguridad Nacional. IV Conclusiones.

\section{CONTEXTO HISTÓRICO}

El final de la Guerra Fría, cuyo elemento más gráfico fue la caída del Muro de Berlín y del eje soviético, supuso el fin de un modelo geopolítico $^{1}$ que estaba asentado sobre la supremacía de los países - o coalición de éstos- que basaban su economía en el dominio del territorio y el potencial armamentístico. Ese modelo estaba caracterizado por un mundo bipolar y predecible. ${ }^{2}$ Al finalizar la II Guerra Mundial, y tras la rigidez de unas posiciones basadas en el poderío militar se produjo una lucha soterrada que se adentraba en lo político y, sobre todo, en lo económico, siendo las multinacionales las que actuaban como una suerte de brazo armado de los gobiernos en liza. Un hecho sobre el que alertaba Jean-Jacques Servan-Schreiber,

${ }^{1}$ El concepto de geopolítica apareció en el siglo xx vinculado al poder del Estado y sus necesidades de gobernar. Desarrollado en la década de los '30 por los geógrafos alemanes Ratzel y Haushofer para justificar la expansión territorial de su país (teoría Lebensraum o espacio vital) bajo la definición del todo el territorio que un país necesita para lograr su autosuficiencia. Todas las potencias mundiales (Rusia, China, Japón y Estados Unidos) tomaron estas ideas para justificar sus políticas expansionistas en pos de lograr los recursos físicos, económicos, ambientales y geográficos para garantizarse su prosperidad.

2 FERRER RODRÍGUEZ, J.: «Seguridad económica e inteligencia estratégica de España», Documento de opinión 85/2011, Instituto Español de Estudios Estratégicos, de 05 de diciembre de 2011, pág. 2. 
fundador del semanario francés L’Express, que calificó como la primera gran guerra sin armas ni fortificaciones. $)^{3}$

La ruptura de ese modelo bipolar de bloques dio paso una nueva etapa en la diplomacia internacional mucho más insegura, caracterizada por la multipolaridad, donde coexisten nuevas manifestaciones de amenazas tradicionales con riesgos y amenazas completamente nuevas ${ }^{4}$, que supone que el sistema internacional se mueva en estos momentos de la geopolítica a la geoeconomía, ${ }^{5}$ caracterizada por una economía financiera fundamentada en el conocimiento y la explosiva circulación de personas, bienes y servicios, que ha puesto al hecho económico en el centro de innumerables conflictos regionales y globales lo que se ha dado en llamar guerra económica ${ }^{6}$ o guerra de cuarta generación. ${ }^{7}$

${ }^{3}$ OLIER ARENAS, E.: «Inteligencia económica» en DÍAZ FERNÁNDEZ, A.M. Conceptos fundamentales de inteligencia, Ed.Tirant lo Blanch, Valencia, 2016, pág. 233.

${ }^{4}$ DÍAZ MATEY, G.: "De la cooperación a la competición: la inteligencia económica en el marco de la Estrategia de Seguridad Nacional 2013», UNISCI Discussion Papers, n35, mayo 2014, pág. 354.

5 FERRER RODRÍGUEZ, J.: Ob.cit., pág. 2.

6 OLIER ARENAS, E.: Ob.cit., pág. 234

7 Decía Von Clausewitz decía que «cada tiempo tiene su forma peculiar de guerra, y en este sentido, en 1989 William Lind escribió el artículo "El rostro cambiante de la guerra: hacia la Cuarta Generación» habla de cuatro generaciones de guerras con una distribución espacio temporal diferente y que obedecen al siguiente esquema:

Guerras premodernas: son guerras de subsistencia que tienen lugar entre Ejércitos más o menos organizados; la supervivencia de la sociedad está ligada al resultado del conflicto. Sus causas serían motivaciones de tipo económico, relacionados con la subsistencia, por el territorio o en razón también de odios ancestrales

Guerra de primera generación: estaría marcada por el desarrollo y consolidación del concepto Estado. Se inicia con las armas de fuego y la formación de ejércitos profesionales al servicio de los estados en reemplazo de milicias mercenarias al mando de diversos poderes en un mismo país, la búsqueda de un mayor poder de fuego llevara a la industrialización de la guerra.

Guerra de segunda generación: Se inicia con la industrialización y la mecanización, su elemento fundamental es la capacidad de movilización de grandes ejércitos burocratizados y el uso de maquinaria bélica con innovaciones en la artillería, la táctica, las comunicaciones y la organización. El desarrollo de un mayor poder de fuego provocó que se usaran trincheras como medio de protección de los soldados, provocando las llamadas guerras de desgaste.

Guerra de tercera generación: se fundamentan en la tecnología. Surgió producto de la mecanización de los ejércitos (particularmente la invención de los tanques en la Gran Guerra) para romper el estancamiento de la guerra de trincheras. Se basa en la velocidad y sorpresa de un ataque, en la base de una superioridad tecnológica sobre el enemigo, impidiendo cualquier ejecución de defensa coordinada del atacado, el ataque se funda en la concentración de fuerzas aéreas y terrestres coordinadas, en la interrupción de comunicaciones del enemigo y en el aislamiento logístico de sus defensas, causando un intencional impacto psicológico aterrador, en esta etapa se ataca masivamente a los civiles para impedir que estos sostengan la industria bélica que necesita el enemigo para continuar la guerra.

(C) UNED. Revista de Derecho UNED, núm. 24, 2019 
La situación de aparente calma militar entre las grandes potencias durante la década de los noventa del siglo pasado, se vio interrumpida abruptamente por la aparición de un nuevo elemento distorsionador con los atentados del 11 de septiembre de 2001. Terroristas árabes atacaban uno de los símbolos más representativos de Estados Unidos, y lo hacían con un medio tan convencional en el uso diario como poco convencional dentro del catálogo de amenazas a la seguridad ciudadana como era la utilización de aviones. Este hecho supuso un cambio radical en las políticas de seguridad nacional e internacional que hasta ese momento se habían venido aplicando, pues este nuevo tipo de conflicto asimétrico provocó y sigue provocando una sensación generalizada de inseguridad en los países teóricamente más poderosos, al tener que enfrentarse a una amenaza más etérea e indeterminada.

\section{CONTEXTO ACTUAL}

Y es que vivimos tiempos convulsos. Si revisamos el catálogo de riesgos y amenazas que recoge la Estrategia Española de Seguridad, podemos comprobar que prácticamente todos se han producido a lo largo de la última década: ataques terroristas indiscriminados en las capitales europeas, piratería marítima, flujo masivo de emigrantes motivados por conflictos armados, cambio en las estructuras político-sociales que son el efecto de una prolongada crisis económica y financiera, etc...

La etapa política de inestabilidad no es nueva — quizás nunca lo haya sido- pues a lo largo de la historia siempre han existido hostilidades entre los hombres y los pueblos. De hecho, desde la década de los '90 una serie de sociólogos han teorizado al respecto; por ejemplo, Ulrich Beck con su ensayo La sociedad del riesgo (1992) y

Guerra de cuarta generación: es la globalización y el retorno al hombre. Comprende a la guerra de guerrillas, la Guerra asimétrica, la Guerra de baja intensidad, la Guerra Sucia, el Terrorismo de Estado u operaciones similares y encubiertas, la Guerra popular, la Guerra civil, el Terrorismo y el Contraterrorismo, además de la Propaganda, en combinación con estrategias no convencionales de combate que incluyen la Cibernética, la Población civil y la Política. En este tipo de guerras no hay enfrentamiento entre ejércitos regulares ni necesariamente entre Estados, sino entre un estado y grupos violentos o mayormente entre grupos violentos de naturaleza política, económica, religiosa o étnica. Al basarse la generación anterior en la superioridad tecnológica llega a surgir un gran poder de ataque militar. La única forma sensata de intentar enfrentar es el uso de fuerzas irregulares ocultas que ataquen sorpresivamente al enemigo, tratando de provocar su derrota al desestabilizar a su rival, es decir, con el uso de tácticas no convencionales de combate. En estas tácticas las grandes batallas desaparecen casi por completo. 
de David Garland La cultura del control (2001) tratan el concepto de inseguridad y exponen como, a pesar de vivir uno de los momentos de mayor paz social e internacional, el desarrollo de nuevas tecnologías ha creado un sentimiento de inseguridad e incertidumbre, en muchas ocasiones injustificado, respecto a la seguridad personal, ya sea en el ámbito de la salud, laboral, física, etc...Asimismo, Zygmunt Bauman en su obra más conocida — La modernidad líquida (2000) - afirma que el presente, a diferencia del pasado es voluble o adaptable, mientras que el pasado, más allá de las interpretaciones que podamos hacer de los hechos, es inamovible; es esa volubilidad la que genera inquietud en las personas que, por lo general, persiguen la estabilidad.

Lo cierto es que actualmente la globalización ha hecho que los Estados hayan perdido competencias a favor de la multilateralidad, han cedido parte de su poder para compartir una serie de responsabilidades (ejemplo claro de lo que es la Unión Europea). La alianza de países ha democratizado las normas patrias, pero ha hecho que los Estados sean más débiles frente a un abanico de viejas y nuevas amenazas de carácter delictivo. Frente a este panorama se puede optar por dos posturas: el aislacionismo (el Brexit británico) o reforzar los lazos internacionales (España y su comunión con la Unión Europea y países sudamericanos).

Estados Unidos tras sufrir los ataques terroristas del 11-S aprobó una legislación que potenció la maquinaria estatal en materia de seguridad e inteligencia, renovando unas estructuras que habían quedado anquilosadas en los métodos de la Guerra Fría, destacando muy especialmente la aprobación de la National Security Strategy (Estrategia de Seguridad Nacional) de 2002 que orientaba claramente a la acción enfocada en la prevención de los ataques contra la nación y sus aliados, y en el desarrollo de agendas de acción cooperativa con otros centros de poder global. ${ }^{8}$

Asimismo, y como efecto imitación que casi todos los países de la órbita occidental realizan de la política de seguridad estadounidense se comenzaron a elaborar normas específicas respecto a la Seguridad Nacional (Reino Unido, Francia, Holanda o Canadá); entre ellas están las estrategias de seguridad nacional en las que se informa a los ciudadanos de los problemas más graves a los que se enfrentan y las formas en la que los gobiernos esperan protegerles. Con las lógi-

8 INSTITUTO ESPAÑOL DE ESTUDIOS ESTRATÉGICOS: «La estrategia de seguridad nacional de los EE.UU.. Aspectos más destacados de su evolución», Documento de Análisis del IEEE 06/2010, julio 2010, pág. 4. 
cas diferencias entre ellas —según los intereses y dimensión de cada Estado- todas las estrategias dan a conocer el contexto internacional de seguridad, los riesgos posibles, los objetivos a conseguir, los instrumentos disponibles y la forma en la que esperan proteger la seguridad nacional.

En España, el corpus legislativo de la Seguridad Nacional, está presidido por la Constitución, para a continuación ser regulada por una ley propia, la Ley 14/2015, de 29 de septiembre de 2015, de Seguridad Nacional que dota de una norma con carácter de ley ordinaria un ámbito específico que hasta la fecha sólo había venido definido específicamente por dos Estrategias Nacionales, y una tercera que ha sido aprobada en 2017. Así, las sucesivas estrategias aprobadas han sido la Estrategia Española de Seguridad. Una responsabilidad de todos, de 2011 (en adelante EES 2011), la Estrategia de Seguridad Nacional. Un proyecto compartido, de 2013 (en adelante ESN 2013) y la Estrategia de Seguridad. Un proyecto compartido de todos y para todos, de 2017 (en adelante ESN 2017). De igual manera, y en un nivel descriptivo, que no normativo, se encuentran los Informes Anuales de Seguridad Nacional, que desde el año 2013 publica el Consejo para la Seguridad Nacional para exponer la evolución que experimentaron los diferentes retos a la Seguridad Nacional. ${ }^{9}$

La Estrategia de Seguridad Nacional facilita el desarrollo de las estrategias de segundo y tercer nivel alineándolas para que persigan los mismos objetivos estratégicos de modo que se aprovechen las sinergias..$^{10}$ Así, además de la Estrategia de Seguridad Nacional, hay estrategias de sectoriales que se ocupan de amenazas específicas - en concreto están aprobadas la Estrategia Nacional de Ciberseguridad, la Estrategia Nacional de Infraestructuras Críticas, Estrategia de Seguridad Marítima Nacional y la Estrategia de Seguridad Energética Nacional-, en otras amenazas, no existe una estrategia ad hoc, sino que el legislador ha optado por dejar su tratamiento en manos de los sectores que tradicionalmente se había ocupado de estos problemas; es el caso del terrorismo y el crimen organizado del que trata la Política Criminal y el Código Penal; o el de la Defensa del que se ocupa el Ministerio Propio, a través de las Directivas de Defensa Nacional.

${ }^{9}$ Consejo de Seguridad Nacional: Informe anual de Seguridad Nacional 2013, pág. 9.

10 BALLESTEROS MARÍN, M.A.: En busca de una Estrategia de Seguridad Nacional, IEEE-Ministerio de Defensa, Madrid, 2016, pág. 18. 


\section{LA INESTABILIDAD ECONÓMICA Y FINANCIERA}

\section{III.a. Conceptos generales}

Cuando se habla de «seguridad», todo el mundo tiene una noción de a lo que se alude, pero existen múltiples definiciones de seguridad. El diccionario de la Real Academia de la Lengua Española (en adelante DRAE) define seguridad como la «cualidad de seguro». Asimismo, se define la palabra seguro como: «libre o exento de peligro, daño o riesgo»; otra definición se corresponde a «cierto, indubitable y en cierta manera infalible».

El psicólogo estadounidense Abraham Maslow en su ensayo «Una teoría sobre la motivación humana» (1943) exponía de forma muy gráfica esta idea en su pirámide de las motivaciones o necesidades individuales. Serán estas necesidades las que hagan que los individuos actúen de una manera u otra para satisfacer sus necesidades y las que en último término justifican la evolución del mundo. Maslow estableció una jerarquía de cinco necesidades para el ser humano. En primer nivel se encontrarían las necesidades biológicas, en el segundo la necesidad de seguridad, en el tercero la afiliación, en el cuarto la estima y en el quinto nivel o más elevado estarían las necesidades espirituales de autorrealización o autoactualización. Es preciso satisfacer razonablemente cada nivel, a criterio del propio individuo, para poder ascender al siguiente nivel.

Las necesidades de seguridad y protección surgen cuando las necesidades biológicas más básicas están cubiertas. En los adultos la necesidad de seguridad viene ligada, en un primer momento por la salvaguarda de los conocidos derechos de primer nivel como la vida y la integridad física y psíquica de ellos y sus allegados; en un segundo escalón del prioridades, y ya en una sociedad desarrollada la seguridad se entiende a nivel socioeconómico y viene reflejada en el ansia de estabilidad, en la preferencia por un trabajo fijo y estable, el deseo de una cuenta de ahorros y de un seguro como el médico, el dental, de desempleo, de incapacidad, de vejez. ${ }^{11}$

Es esta idea la que enlaza doblemente la motivación del presente trabajo, por un lado la seguridad y por otro la economía, que si bien Maslow entendía como una necesidad individual tuvo un desarrollo teórico hacia la necesidad colectiva. En este sentido, la ONU en su Informe sobre el Desarrollo Humano (PNUD o

11 MASLOW, A.H.: Motivación y personalidad, Ediciones Díaz de Santos, S.A., Madrid, 1991, pág. 26.

(c) UNED. Revista de Derecho UNED, núm. 24, 2019 
United Nations Development Program) de 1994 dio origen al concepto de «seguridad humana» pretendiendo cambiar el enfoque de la supervivencia de los Estados a la seguridad y el bienestar de los individuos. ${ }^{12}$

Así, la PNUD considera que la relación de amenazas contra la seguridad humana puede agruparse en siete categorías principales ${ }^{13}$ : Seguridad alimentaria, Seguridad de la salud, Seguridad ambiental, Seguridad personal, Seguridad de la comunidad, Seguridad política y Seguridad económica.

Respecto de esta última, tema en el que se centra el presente trabajo, el Informe del PNUD la entiende como un ingreso básico asegurado, por lo general como resultado de un trabajo productivo y remunerado o, como último recurso, de algún sistema de seguridad financiado con fondos públicos. ${ }^{14}$

Independientemente del conocimiento que se tenga de la Ciencia Económica, la importancia de ésta es indudable. La economía impregna casi todos los ámbitos de nuestra vida (somos homo economicus según la Escuela Neoclásica), de manera que el resto de amenazas a la seguridad nacional también influyen directa o tangencialmente sobre la economía y ésta sobre la seguridad y bienestar de los ciudadanos. Y a pesar de ser uno de los asuntos más analizados por los especialistas, ya sea por economistas, sociólogos, politólogos, juristas, etc..., sus pronósticos distan mucho de ser certeros, como puede observarse, y padecerse con la crisis económica y financiera que va camino de cumplir una década. Ninguna materia como la Economía, permite visualizar la falibilidad de una ciencia, en este caso las ciencias económicas, que aún tratándose de una ciencia social, está basada en análisis cuantitativos tiende a realizar proyecciones y predicciones a medio y largo plazo.

La economía ha pasado a ser una continuación de la guerra. Las ambiciones geoeconómicas de las naciones de nuestro entorno y la existencia de una guerra económica encubierta, incluso entre países considerados entre sí como aliados, ha sido un factor determinante para que los países occidentales hayan potenciado de forma inequívoca la misión económica ofensiva de sus servicios de inteligencia. Aquellas naciones que consigan desarrollar un sistema de inteligen-

12 CENTER FOR AMERICAN PROGRESS: «Sustainable security 101 » disponible en https://cdn.americanprogress.org/wp-content/uploads/issues/2009/08/pdf/ ss101.pdf, pág. 02 [consultado el 09/06/2018].

13 ONU: Informe sobre Desarrollo Humano, 1994, pág. 28.

${ }^{14}$ Ibidem., pág. 28. 
cia económica efectivo consiguen una ventaja comparativa clave en el actual contexto. ${ }^{15}$

La Ley 36/2015, de 28 de septiembre, de Seguridad Nacional no pasó por alto la importancia de la seguridad económica y financiera. A este respecto, esta norma hace referencia en su preámbulo a que la estabilidad económica forma parte de los nuevos desafíos que la Seguridad Nacional tiene en cuenta debido a su complejidad, que desborda las fronteras de categorías tradicionales como la defensa, la seguridad pública, la acción exterior y la inteligencia, así como de otras más recientemente incorporadas a la preocupación por la seguridad, como el medio ambiente, la energía, los transportes y el ciberespacio. Por este motivo considera a la seguridad económica y financiera como ámbito de especial interés para la Seguridad Nacional, que requiere una atención específica por resultar básicos para preservar los derechos y libertades, así como el bienestar de los ciudadanos, y para garantizar el suministro de los servicios y recursos esenciales (art.10).

Asimismo, las Estrategias de Seguridad (antecesoras de la precitada Ley) ya consideraron que el ámbito económico supone un factor de riesgo o amenaza a la Seguridad Nacional. En este sentido, cada estrategia lo define de manera diferente: la EES 2011 se refiere a esta amenaza como "Inseguridad económica y financiera», mientras la ESN 2013 lo hace como "Inestabilidad económica y financiera». La ESN 2017, con un nuevo cambio de nomenclatura, evita tratar esta inestabilidad con la palabra «amenaza» y lo trata como un «desafío». No obstante, podemos considerar que las sucesivas Estrategias asumen lo marcado por sus predecesoras actualizando o matizando pequeños detalles.

A tales efectos, las Estrategias de Seguridad consideran que la Seguridad Económica es una parte integral y requisito esencial de la Seguridad Nacional, debido a su repercusión en la puesta en marcha de actuaciones gubernamentales y en el bienestar de los ciudadanos. Un modelo económico sostenible ${ }^{16}$ está en la base

15 FERRER RODRÍGUEZ, J.: Ob.cit., pág. 3, citando a HASTEDT, Glenn (2005). Seeking economic security through intelligence. Londres, International Journal of Intelligence and CounterIntelligence.

${ }^{16}$ La economía sostenible es un concepto que apareció por primera vez en 1987 a través del Informe Brundtland en la Comisión Mundial de Medio Ambiente y Desarrollo de las Naciones Unidas. En él se expone que los recursos de la tierra bastan para satisfacer las necesidades humanas, pero hay una gran desigualdad territorial y las capacidades de los países y de los ciudadanos no son las mismas. La función de la economía sostenible debe ser la de satisfacer las necesidades de las generaciones presentes sin comprometer las posibilidades de las del futuro para atender sus 
de la estabilidad social a la vez que aporta los recursos necesarios para la seguridad. ${ }^{17} \mathrm{La}$ inestabilidad económica y financiera es uno de los principales riesgos y amenazas actuales, no sólo por la conflictividad política y social que genera, sino también porque alimenta y refuerza otros riesgos existentes. ${ }^{18}$ De ahí la necesidad de adoptar un enfoque integral, que no sólo aborde los aspectos estrictamente económico-financieros, sino que contemple también su dimensión de seguridad. ${ }^{19}$

\section{III.b. Causas de la inestabilidad económica y financiera.}

Las amenazas y desafíos a la seguridad económica pueden ser de muy diversa naturaleza, no exclusivamente económica, y normalmente sus efectos son transversales, materializándose en más de un ámbito. ${ }^{20}$ Entre estos factores están:

\section{a) del propio funcionamiento del sistema. ${ }^{21}$}

a.1. La interdependencia económica, especialmente en el plano económico-financiero por la gran interdependencia existente, exigiendo a los Estados, las organizaciones y los organismos internacionales respuestas rápidas a los cambios que acontecen ${ }^{22}$. La globalización ha difuminado las fronteras entre seguridad interior

propias necesidades, de tal manera que los recursos que se consumen, no deben ser superiores a los que genera la naturaleza.

En España este concepto ha tenido su plasmación normativa a través de la Ley 2/2011, de 4 de marzo, de Economía Sostenible, que en su artículo 2 define la economía sostenible como un patrón de crecimiento que concilie el desarrollo económico, social y ambiental en una economía productiva y competitiva, que favorezca el empleo de calidad, la igualdad de oportunidades y la cohesión social, y que garantice el respeto ambiental y el uso racional de los recursos naturales, de forma que permita satisfacer las necesidades de las generaciones presentes sin comprometer las posibilidades de las generaciones futuras para atender sus propias necesidades. Esta ley se elaboró sobre la base de la Estrategia para una Economía Sostenible, aprobada por el Consejo de Ministros en noviembre de 2009, y se trata de una norma ómnibus que incluye un variado elenco de iniciativas legislativas, reglamentarias y administrativas, así como la promoción de reformas en ámbitos específicos de la economía española con la finalidad de lograr un crecimiento equilibrado y duradero en el ámbito económico, medioambiental y social; tarea para la que será necesaria la contribución pública y privada.

17 EES 2011, pág. 55.

18 ESN 2013, pág. 28.

19 ESN 2017, pág. 72.

${ }^{20}$ ESN 2017, pág. 72.

21 ESN 2013, pág. 28.

${ }^{22}$ EES 2011, pág. 55 y ESN 2013, pág. 28-29. 
y exterior, y aunque las fronteras políticas siguen existiendo, en la práctica, la facilidad de tránsito por ellas de personas, bienes materiales e información hace sumamente difícil clasificar y compartimentar territorialmente el origen y los efectos de los riesgos y amenazas. $^{23}$

a.2. las crisis financieras sistémicas. Está demostrado que la economía se mueve en ciclos económicos más o menos regulares en el tiempo. ${ }^{24}$ El llamado ciclo económico de expansión y depresión era un elemento con el que ya estaban familiarizados todos los hombres de negocios desde el siglo $\mathrm{XIX}^{25}$, y a pesar de esta constancia, los economistas no aciertan a dar con la tecla que les permita anunciar con fiabilidad cuándo se inicia o finaliza el momento negativo del ciclo económico.

La falta de seguridad económica y el estallido de crisis sistémicas pueden generar nacionalismo o proteccionismo económico. El rápido crecimiento de las economías emergentes y la competencia por los recursos podrían afectar al normal suministro de éstos y/o provocar subidas abruptas de precios. ${ }^{26}$ Los riesgos de carácter económico se han evidenciado con singular trascendencia en los últimos años, tras la aparición de esta profunda crisis, que ha reducido la resiliencia económica de España. En consecuencia, la economía española y el propio bienestar social se han visto afectados. ${ }^{27}$

b) de desequilibrios macroeconómicos — públicos o privados- de los mercados, ${ }^{28}$ influenciados en gran parte por las políticas económicas practicadas por los gobiernos.

La volatilidad de los mercados, la innovación tecnológica, el desarrollo de las comunicaciones y la logística, la complejidad y competitividad de los sistemas de producción o las bruscas variaciones en el precio de los alimentos, las materias primas y la energía, exigen a los Estados una capacidad de reacción inmediata y contundente, para que su sistema se adapte a la nueva situación, sin verse afectado seriamente y evitando asimismo escenarios de

${ }^{23}$ BAÑOS, P.: Así se domina el mundo. Desvelando las claves del poder mundial, Ed.Ariel/Planeta, S.A. Barcelona, 2017, pág. 31.

${ }^{24}$ Los ciclos económicos, según su duración pueden clasificarse en cortos (cuarenta meses), medianos (entre seis y nueve años) o largos (sesenta años).

${ }^{25}$ HOSBAWM, E.: Historia del siglo XX (13. ${ }^{a}$ edición), Ed.Crítica, S.L., Barcelona, 2009, pág. 93.

${ }^{26}$ EES 2011, pág. 55.

27 ESN 2013, pág. 29.

28 ESN 2013, pág. 28. 
tanta gravedad como el colapso económico o financiero tanto del sector público como del privado)..$^{29}$

c) de la actuación desestabilizadora o ilegal de agentes económicos. ${ }^{30}$

Posibilidad de que aparezca una serie de elementos y actores que pueden configurar una guerra de cuarta generación, donde dichos actores asimétricos pueden operar solos o apoyados por actores estatales para desestabilizar nuestra economía mediante ataques coordinados, principalmente sobre el valor nuestras compañías cotizadas, pero también manipulando el precio de otros activos estratégicos mediante el ataque a los llamados «cuellos de botella» del sistema financiero. ${ }^{31} \mathrm{El}$ creciente peso de lo mediático en el mundo económico lo hace vulnerable a maniobras de desestabilización y abre la puerta al posible desplazamiento de los conflictos competitivos desde el ámbito de los productos y mercados al de la influencia, a través de la alteración del ánimo de consumidores finales, prescriptores o líderes de opinión. ${ }^{32}$ En este ámbito nos encontramos frente a un nuevo neologismo: las fake news, un anglicismo que hace referencia a noticias falsas que persiguen influir y confundir a un determinado espectro de la población $-\mathrm{O}$ sus decisores- para desestabilizar su conducta. Las noticias falsas no son una materia novedosa en un campo de la estrategia, pero sí su actual influencia, incrementada exponencialmente por la transmisión y acceso a las nuevas tecnologías y redes sociales.

c.1. la especulación. Este concepto sólo aparece recogido en la EES 2011. Para el DRAE la especulación es la operación comercial que se practica con mercancías, valores o efectos públicos, con ánimo de obtener un lucro. En una economía de libre mercado es lícita la especulación dentro de los límites marcados por la Ley (qué es si no, todo el sistema bursátil, en el que entran en juego dinámicas de oferta y demanda de inversores). La especulación fuera de estos límites señalados, que puede ser considerada como un tipo de guerra económica. Sobradamente conocidos en la literatura económica son los ataques que George Soros ${ }^{33}$ realizó

${ }^{29}$ ESN 2013, pág. 29.

30 EEN 2011, pág. 15 y ESN 2013, pág. 28

31 FERRER RODRÍGUEZ, J.: Ob.cit., pág. 4.

32 MARTÍN BARBERO, I.: «Inteligencia económica: tan lejos, tan cerca», Revista Inteligencia y Seguridad n. ${ }^{2}$, Plaza y Valdés Editores, S.L., Madrid, 2007, pág. 117.

${ }_{33}$ George Soros (1930-) es financiero de origen húngaro, que desde 1956 trabaja en Estados Unidos en varias entidades financieras ligadas al mundo de la inversión. Su fama como agresivo especulador le hace aparecer como una figura recurrente en diferentes escenarios de discusión política. Las últimas noticias le sitúan como uno de los financiadores del actual independentismo catalán. 
contra la libra esterlina en 1992, forzando al Banco de Inglaterra gastar hasta 50.000 millones de dólares tratando de frenar el desplome del valor de su moneda. Pero las reservas de divisas del organismo tenían un límite y el mercado pudo más, y el Banco Central inglés tuvo que devaluar su moneda y abandonó el Sistema Monetario Europeo.

c.2. las actividades delictivas. La estrategia de seguridad de 2017 menciona el fraude, la corrupción, el blanqueo de capitales y las interrupciones de los sistemas de comercio e infraestructuras que soportan los flujos comerciales ${ }^{34}$. No obstante, entre las infracciones delictivas cabría incluir el catálogo de delitos contra el patrimonio y contra el orden socioeconómico (título XIII del Código Penal). Las amenazas más recurrentes son el Fraude a la Seguridad Social y la Hacienda Pública nacional y comunitaria, la explotación laboral, el contrabando, la falsificación de productos, la evasión de divisas, el blanqueo de capitales y la corrupción. ${ }^{35}$

c.3. los tráficos ilícitos que ponen en riesgo la estabilidad económica, la financiación de los servicios públicos, los derechos sociales y el bienestar de los ciudadanos. ${ }^{36}$ Por primera vez una Estrategia menciona el problema que el tráfico ilícito de seres humanos supone, no sólo a nivel humanitario, sino a nivel de un sobreesfuerzo en los servicios sociales del país de acogida; de manera, se relaciona con el otro desafío que recoge la ESN 2017 que son los flujos migratorios irregulares.

d) del deficiente funcionamiento de los organismos supervisores y reguladores. ${ }^{37}$

Se trata de una inestabilidad accidental la que procede de errores involuntarios (no intencionales) de los agentes económicos. La creciente «complejidad y automatismos» del sistema económico y financiero hacen cada vez más posibles este tipo de fenómenos. ${ }^{38}$ Como toda institución humana, es susceptible de errar. Su estructura, siempre mejorable, está sujeta a la falibilidad de sus miembros, ya sea por impericia, ya por imprudencia o por una deliberada mala praxis (por ejemplo, permisos que recibió Bankia para

${ }^{34}$ ESN 2017, pág. 73.

35 Consejo de Seguridad Nacional: Informe Anual de Seguridad Nacional 2015, pág. 77.

36 ESN 2017, pág. 73.

37 ESN 2013, pág. 28.

38 ESTEVE MORA, F.: "Inestabilidad económica y financiera», en DE LA CORTE IBÁÑEZ, L. y BLANCO NAVARRO, J.M. ${ }^{a}$. : Seguridad nacional, amenazas y respuestas, LID Editorial Empresarial, S.L., Madrid, 2014, pág. 150. 
salir a Bolsa), pero también tienen una importancia destacada la intervención en Economía de la confluencia de las diferentes legislaciones de los países que se supone deben jugar con unas mismas reglas de juego. Así, los paraísos fiscales constituyen una de las grandes amenazas para la estabilidad económica y financiera no solo nacional sino, igualmente internacional. En este sentido, la existencia de paraísos fiscales es un factor desestabilizador del sistema en cuanto propicia actuaciones de blanqueo de capitales. ${ }^{39}$ La falta de ingresos tributarios que se deriva del uso abusivo de estos territorios supone un incremento de la carga tributaria que deben soportar el resto de contribuyentes. ${ }^{40}$ De igual manera, detectado un aumento en la actividad delictiva del blanqueo de capitales, el Consejo de Seguridad Nacional justifica el aumento de este tipo delictivo por: la situación geoestratégica de España, como país de tránsito hacia otros Estados; el crecimiento económico que convirtió a España en un mercado atractivo, lo cual ha sido aprovechado igualmente por las organizaciones criminales; la libre circulación de personas, mercancías y capitales dentro del ámbito de la UE, que ha permitido a estas organizaciones criminales una mayor libertad de acción; y posiblemente una mayor laxitud en el ámbito de la represión penal que en otros países. ${ }^{41}$

e) de causas externas.

e.1. los fallos en infraestructuras críticas. Las amenazas sobre las infraestructuras críticas tienen un apartado propio en cada una de las Estrategias hasta ahora publicadas. La seguridad económica y financiera está ligada a la seguridad del complejo sistema de instalaciones, redes, sistemas y equipos físicos y de tecnología de la información, es decir, las infraestructuras críticas, cuyo funcionamiento es indispensable para el normal desenvolvimiento del sector financiero..$^{42}$

e.2. Las guerras económicas. Es curioso observar cómo, quizás por una excesiva corrección política del legislador, las sucesivas estrategias han omitido que una amenaza a la estabilidad económica y financiera son las guerras económicas; más llamativo si cabe es que, si se tiene en cuenta que el concepto de estratégico

39 ESN 2013, pág. 28.

40 Consejo de Seguridad Nacional: Informe Anual de Seguridad Nacional 2014, pág. 87.

${ }^{41}$ Consejo de Seguridad Nacional: Informe Anual de Seguridad Nacional 2013, pág. 60.

${ }_{42}$ Consejo de Seguridad Nacional: Informe Anual de Seguridad Nacional 2014, pág. 87. 
tiene orígenes militares. ${ }^{43}$ Puede definirse la guerra económica como el uso de instrumentos económicos para lograr una ventaja, ya sea política o económica, en una disputa en la que al menos uno de los actores enfrentados es explícita o implícitamente un Estado. ${ }^{44}$

Si al comienzo de este artículo se hizo referencia a como la guerra es una continuación de la política por otros medios (Clausewitz), y tomando como cierta la máxima de que el dinero mueve el mundo, en la Historia podemos encontrar multitud de ejemplos de guerras económicas, ora interestatales (entre Estados), ora intraestatales (dentro de un mismo país), ora extraestatales (que enfrentan los intereses de un Estado con los agentes extranjeros no estatales). Al fin y al cabo, si se busca una justificación de los conflictos bélicos de todos los tiempos, hallaremos el componente económico, ya sea en aras de conseguir espacio físico donde expandirse, en busca de recursos materiales o la sumisión de otros pueblos que sirvan a los intereses del vencedor (ejemplos abundan, desde la Guerra del Opio, guerras coloniales, etc...). En la actualidad, la visceralidad o brutalidad de los campos de combate pasa a un segundo plano; es lo que ha venido a denominarse como softpower o poder blando en el que cobran especial protagonismo las políticas orientadas a ejercer influencia a través de la industria cultural y del ocio, en el que la innovación, la creatividad y la transferencia de conocimiento son condiciones esenciales. ${ }^{45}$ En la virtualidad que nos ofrece la globalización se emprenden políticas de restricción del libre comercio, como la actual emprendida por la administración Trump con la subida de aranceles a las importaciones, que ya tiene su respuesta por parte de la Unión Europea y China.

\section{III.c. Líneas de acción estratégica}

Las líneas de acción estratégica vienen desarrolladas en las Estrategias de Seguridad - en la EES 2011 como un apartado del epígrafe de la inseguridad económica y financiera; y en las ESN 2013 y 2017 con un capítulo específico $\left(4 .^{\circ}\right.$ y $5 .^{\circ}$, respectivamente) dedicado a todas las amenazas y desafíos desarrollados en capítulos anterio-

${ }^{43}$ FREEDMAN, L.: Estrategia. Una historia, Ed.La esfera de los libros, S.L., Madrid, 2016, pág. 16.

${ }^{44}$ ESTEVE MORA, F.: op. cit., pág. 156.

${ }^{45}$ GONZÁLEZ CUSSAC, J.L.y LARRIBA HINOJAR, B.: Inteligencia económica y competitiva. Ed.Tirant lo Blanch, Valencia, 2011, pág. 17. 
res. Las líneas de acción estratégica suponen un catálogo de propuestas para hacer frente a las referidas amenazas.

El dinamismo de una economía de mercado conlleva necesariamente cierta inestabilidad que hay que gestionar, además de hacer frente a las amenazas y riesgos o desafíos que puedan surgir. Para ello son necesarias las siguientes líneas de acción: ${ }^{46}$

1. Potenciación de un modelo de crecimiento económico sostenible que minimice los desequilibrios tanto públicos como privados, potencie la productividad, el tejido empresarial, la innovación y la competitividad, intensifique los sectores de alto valor añadido, cree empleo de calidad, mantenga unas finanzas públicas saneadas y la estabilidad de precios a lo largo del ciclo económico, y garantice la cohesión social ${ }^{47}$, y una distribución justa de las rentas, pilares fundamentales de la estabilidad y el crecimiento económico tanto en el ámbito nacional, como en el internacional. ${ }^{48}$

Respecto a los desequilibrios de los mercados, la crisis económica y financiera que empezó en 2007-2008 ha mostrado, una vez más, la importancia de prevenir y corregir los efectos de los fallos de mercado. El normal funcionamiento del sistema y algunas actuaciones de los agentes económicos pueden, aun siendo legales, generar perturbaciones. Mitigarlas requiere una regulación y supervisión efectiva, a la que es fundamental incorporar a los agentes económicos y sociales. De especial importancia es el sistema financiero, por su riesgo sistémico. ${ }^{49}$

2. Establecimiento de un marco socio-laboral que contribuya a una gestión eficaz de las relaciones laborales, basado en el diálogo social con vistas a la adopción de medidas consensuadas que coadyuven a reducir los niveles de conflictividad y favorezcan la paz social, que facilite la estabilidad en el empleo, la creación de puestos de trabajo y la eficiencia del mercado de trabajo.

3. Promoción de una economía internacional abierta con un sistema estable de libre comercio e inversión en el marco de los foros internacionales en los que está presente España. Se fomentarán los consensos internacionales para dotar de mayor transparencia al siste-

${ }^{46}$ EES 2011, pág. 55.

47 ESN 2013, pág. 44.

48 EES 2011, pág. 56.

49 EES 2011, pág. 56. 
ma financiero. Se promoverá la seguridad jurídica en los entornos de inversión de las empresas españolas con actividad en el exterior. ${ }^{50}$

4. Refuerzo de los actuales mecanismos de regulación y supervisión, para conseguir que su labor sea efectiva y se eviten crisis sistémicas. Establecimiento de nuevos mecanismos de regulación y supervisión que garanticen una gobernanza económica y financiera global eficaz. ${ }^{51}$ Esta gobernanza internacional debe promover la transparencia y luchar contra la corrupción, impulsar un crecimiento inclusivo y equitativo y favorecer una mejor representatividad en las instituciones reguladoras. ${ }^{52}$ Se cooperará activamente en la construcción de un gobierno económico europeo con instrumentos comunes y políticas económicas coordinadas que incluirán igualmente el estudio de medidas de vigilancia de los paraísos fiscales. ${ }^{53}$ La Unión Económica y Monetaria debe ser fuente de confianza, crecimiento y prosperidad..$^{54}$

5. Fomento de los mecanismos de coordinación adecuados que permitan el desarrollo de la seguridad económica y de sus herramientas de apoyo — como por ejemplo, el Sistema de Inteligencia Económica (SIE). ${ }^{55}$

La necesidad de la creación de este SIE fue plasmada en la Estrategia Española de Seguridad 2011: En el ámbito interno y, en consonancia con lo hecho por otros países, se establecerá un Sistema de Inteligencia Económica (SIE) con la misión de analizar y facilitar información económica, financiera y empresarial estratégica relevante, oportuna y útil para apoyar la acción del Estado y una mejor toma de decisiones. Este Sistema permitirá compartir conocimiento, crear sinergias, evitar duplicidades y facilitar la adopción de posiciones comunes en las Administraciones Públicas. En estrecha relación también con los diferentes actores económicos, contribuirá a las labores de seguridad del Estado facilitando la detección y prevención de actuaciones contrarias a los intereses económicos, financieros, tecnológicos y comerciales de España en sectores estratégicos. ${ }^{56}$

Asimismo, en sus conclusiones, la Estrategia de 2011, en su capítulo 5 explicita que el desarrollo del SIE deber realizarse en colaboración con el sector privado, para la obtención y análisis de in-

\footnotetext{
50 ESN 2013, pág. 44.

${ }^{51}$ ESN 2013, pág. 44.

52 ESN 2017, pág. 109.

53 ESN 2013, pág. 44.

${ }^{54}$ ESN 2017, pág. 109.

55 ESN 2013, pág. 44.

56 EES 2011, pág. 44.
} 
formación económica, financiera y empresarial relevante para la seguridad, que permita detectar y prevenir actuaciones contrarias a nuestros intereses y apoyar la acción del Estado y una mejor toma de decisiones en este ámbito. ${ }^{57}$

Lo cierto es que a día de hoy el SIE o cualquier otra estructura de similares características sigue sin arrancar debido principalmente a las tensiones internas entre distintos ministerios, luchas de poder entre distintas partes de la Administración española que entienden que deberían hacerse cargo de estas funciones (Ministerio de Economía, Presidencia...) y las reticencias que tiene el Centro Nacional de Inteligencia a "externalizar» este tipo de funciones incluyendo a otros agentes fuera de su Casa con los problemas que les está dando el CICO y el CNCA y con los problemas que tienen de reorganización de personal, ahora que el final de ETA parece más cerca. ${ }^{58}$

Sin embargo, evitar duplicidades y compartir información dentro de la propia Administración sería paradójicamente uno de los objetivos principales del SIE con el fin de generar posiciones comunes algo que parece ser que choca a día de hoy con las luchas internas de poder dentro de los distintos Ministerios. ${ }^{59}$

6. Esfuerzo estratégico de acción y comunicación permanente en favor de la reputación e imagen de España, defensa de nuestros intereses en foros e instituciones económicas y apoyo a la internacionalización de empresas y emprendedores españoles con el objetivo de contribuir a construir una «marca España» sólida y positiva, tanto desde el entorno público como el privado. ${ }^{60}$

- La fortaleza económica de España, y por tanto su seguridad, dependen en buena medida de nuestra capacidad para defender y proyectar los intereses económicos españoles y de nuestras empresas en el exterior. Para ello es crucial potenciar la presencia de España en foros e instituciones económicas y apoyar la expansión de empresas y emprendedores españoles en mercados internacionales.

- La interdependencia de nuestra economía hace a España más próspera pero también más vulnerable. Una puesta en cuestión de la reputación adquirida puede tener un impacto en los

57 EES 2011, pág. 85.

58 SANZ ROLDÂN, F: «El Centro Nacional de Inteligencia ante el reto de la seguridad Económica», Inteligencia y Seguridad, n. 9 (Diciembre de 2010), pág. 18.

59 DÍAZ MATEY, G.: «Ob.cit., pág. 363.

${ }^{60}$ ESN 2013, pág. 44. 
mercados, especialmente en tiempos de incertidumbre o crisis. Contrarrestarlo pasa por potenciar la «marca España», con un esfuerzo estratégico de acción y comunicación permanente al que deben contribuir tanto el Estado como las empresas. Para ello será preciso mantener en todo momento el difícil equilibrio entre transparencia, pues la falta de información puede hacer temer un panorama peor que la propia realidad, y protección de información estratégica.

- Hay que gestionar adecuadamente las consecuencias para la seguridad de la presencia de empresas extranjeras en los servicios e infraestructuras críticas, respetando siempre la legislación de la UE y las normas internacionales, y sin dificultar la inversión extranjera directa. ${ }^{61}$

7. Definición de un procedimiento de estrecha cooperación entre las entidades privadas y las autoridades públicas responsables de la seguridad de las infraestructuras y los servicios financieros. ${ }^{62}$

- Algunos servicios e infraestructuras económicas y financieros son esenciales para el normal funcionamiento del país. Basta pensar qué pasaría si las tarjetas de crédito o las transferencias interbancarias no funcionasen durante 24 horas. La creciente complejidad técnica, las catástrofes naturales o las actividades delictivas constituyen amenazas que hay que gestionar. Se debe intensificar el intercambio de información entre autoridades regulatorias y supervisoras y operadores privados, desarrollar más planes de contingencia y de continuidad de negocio frente a riesgos de naturaleza financiera y operativa, y elaborar un mapa de riesgos, capacidades, expertos y mejores prácticas.

- La seguridad de las infraestructuras y servicios financieros es responsabilidad de las propias entidades privadas y de las autoridades públicas. El Comité de Estabilidad Financiera (CESFI) - integrado por el Ministerio de Economía y Hacienda, el Banco de España y la Comisión Nacional del Mercado de Valores (CNMV) - es el responsable del desarrollo coordinado de planes preventivos y de actuación en materia de estabilidad financiera y de prevención y gestión de crisis. ${ }^{63}$

${ }^{61}$ EES 2011, pág. 58.

62 ESN 2013, pág. 44.

${ }^{63}$ EES 2013, pág. 59. 
Sobre la base de las líneas de acción estratégicas marcadas por la Estrategia de Seguridad Nacional, a partir de 2013 se empezaron a publicar los Informes anuales de Seguridad Nacional que, aprobados por el Consejo de Seguridad Nacional para su posterior presentación y debate en las Cortes, realizan un diagnóstico completo de la evolución de los retos de la Seguridad Nacional, los valora según su manifestación y traza su posible desarrollo futuro, siempre con un enfoque integral, toda vez que los desafíos a la Seguridad Nacional se interrelacionan debido a su elevada transversalidad, afectan a las competencias de varios actores y solo desde una perspectiva amplia es posible analizarlos y dimensionarlos correctamente. Los informes anuales en seguridad nacional son un instrumento que permite evaluar el grado de cumplimiento de la Estrategia de Seguridad Nacional y, en futuros procesos de revisión de la Estrategia, identificar el surgimiento de nuevos desafíos a la Seguridad Nacional, la evolución de los ya incluidos y la posible actualización de las Líneas de Acción Estratégica con la finalidad de proteger la libertad y el bienestar de los españoles, garantizar la defensa de España y sus principios y valores constitucionales, así como contribuir junto a nuestros socios y aliados a la seguridad internacional en el cumplimiento de los compromisos asumidos. Este Informe presenta la evolución del Sistema de Seguridad Nacional, así como un balance del estado de sus doce ámbitos componentes según la desarrollo de los retos existentes en la materia durante el año y como consecuencia de las realizaciones llevadas a cabo. ${ }^{64}$

\section{III.d. Potenciadores del riesgo}

Aunque sólo la EES 2011 dedica un capítulo al concepto de potenciador del riesgo, se menciona de soslayo en la ESN 2013 y desaparece cualquier mención a ellos en la ESN 2017, son plenamente aplicables a todas las amenazas. La EES 2011 no llega a definir expresamente el concepto de potenciador, pero sí los cataloga como un fenómeno global que "propicia» la propagación o transformación de las amenazas y riesgos, «incrementando» nuestra vulnerabilidad. Es decir, que sin ser en sí mismos un riesgo o amenaza, pueden desencadenarlos o agravarlos ${ }^{65}$.

${ }^{64}$ Información extraída de la web del Gabinete de la Presidencia de Gobierno, Departamento de Seguridad Nacional, disponible en http://www.dsn.gob.es/sites/ dsn/files/CIV_Informe\%20Anual\%20de\%20Seguridad\%20Nacional.pdf [consultado el 21/07/2017].

${ }^{65}$ ESN 2013, pág. 21. 
A este respecto, existe un exhaustivo realizado por el Instituto Español de Estudios Estratégicos (IEEE), publicado por el Ministerio de Defensa en su Cuadernos de Estrategia n. ${ }^{\circ} 159$ de febrero de 2013 «Los potenciadores del riesgo», imprescindible para profundizar en este tema.

Los potenciadores de riesgo que afectan a la estabilidad económica y financiera son:

\section{- Disfunciones de la globalización}

El Consejo de Europa define la globalización como «una variedad de cambios económicos, culturales, sociales y políticos que han dado forma al mundo en los últimos 50 años, desde la muy celebrada revolución de la tecnología de la información a la disminución de las fronteras nacionales y geopolíticas en la cada vez mayor circulación transnacional de bienes, servicios y capitales». ${ }^{66}$

El incremento de flujos internacionales de personas, información, bienes y servicios ha facilitado la difusión del conocimiento y un mayor crecimiento económico en todo el mundo. Cientos de millones de personas están incorporándose al sistema económico mundial y saliendo de la pobreza.

La globalización también tiene un lado menos positivo. La interconexión económica puede facilitar desequilibrios macroeconómicos y crisis sistémicas de rápido contagio. Ha incrementado la desigualdad de rentas, lo que puede causar inestabilidad política y social. La incorporación de cientos de millones de nuevos consumidores puede producir escasez de recursos, y una mayor competencia por éstos, generar conflictos. En este contexto, España puede verse afectada por circunstancias y hechos gestados en lugares muy lejanos. ${ }^{67}$

\section{- Desequilibrios demográficos}

Según la ONU, la población mundial alcanzará los 7.600 millones de personas en 2020, frente a los 6.900 actuales. Este crecimiento demográfico, que se dará sobre todo en países pobres de Oriente Próximo, África y ciertas zonas de Asia, generará tensiones por los recursos, ante el lícito anhelo de estas nuevas masas de población de alcanzar los niveles de consumo y bienestar de las sociedades desarrolladas.

${ }^{66}$ Disponible en la web https://www.coe.int/es/web/compass/globalisation [consultado el 05/09/2018].

${ }^{67}$ EES 2011, pág. 34. 
El crecimiento en estas regiones convive ya con el envejecimiento de la población en Europa y en las sociedades desarrolladas - también en China-, debido a las bajas tasas de natalidad y al incremento de la esperanza de vida.

Este desequilibrio entre población activa y pasiva plantea, para nuestro país y para gran parte de Europa, el reto de preservar los modelos de cohesión social y de Estado del bienestar.

Es previsible que la población inmigrante suavice este proceso y supla la prestación de muchos servicios esenciales. En nuestro caso, seguirá incrementándose la presión inmigratoria en las fronteras, dada la frustración y la falta de las salidas de la población mayoritariamente joven de los países más pobres. Hay que gestionar adecuadamente este fenómeno. Es indispensable para sostener el modelo social europeo y para generar un alto grado de competitividad. Al mismo tiempo, puede desatar consecuencias que deben afrontarse como el racismo, la xenofobia o los problemas de integración. ${ }^{68}$

\section{- Pobreza y desigualdad}

La miseria y la desigualdad excluyen a muchos seres humanos de los avances y las posibilidades del progreso. En la actualidad, más de 1.000 millones de personas viven en condiciones de pobreza extrema en el mundo, lo que además de una injusticia supone un obstáculo para el progreso y la estabilidad y seguridad internacionales. Así ocurre en áreas con las que España mantiene una relación de vecindad geográfica o cultural, como en la vertiente sur del Mediterráneo, África o algunas zonas de Iberoamérica.

España no puede soslayar esta realidad. La desigualdad económica entre las dos orillas del Mediterráneo es notoria. Los países del África subsahariana se han visto excluidos de un mundo cada vez más rico, hasta el extremo de que en esta área se encuentran 23 de los 25 países con el Índice de Desarrollo Humano (IDH) más bajo. En África se dan la mayoría de los actuales conflictos, en unas condiciones extremas que son caldo de cultivo para radicalismos de todo tipo.

La pobreza y la desigualdad también existen en las regiones más prósperas, incluida Europa, donde el 17\% de la población vive en situación de riesgo de pobreza y el $20 \%$ con mayores ingresos posee cinco veces más que el $20 \%$ con ingresos más bajos. Uno de

68 EES 2011, pág. 34-35. 
los objetivos de la Estrategia 2020 de la UE es la reducción de la pobreza en la Unión, sacando de la miseria y la exclusión a 20 millones de personas. ${ }^{69}$

\section{- Cambio climático}

La variación del clima global durante los últimos años es un proceso cierto, cuyo impacto ya se siente, que exige respuestas en el momento presente y que plantea, a medio y largo plazo, retos de gran trascendencia para la sociedad mundial. Desatará conflictos por la escasez de recursos, disparará el número de refugiados climáticos y agravará la pobreza en muchas sociedades, incrementando la fragilidad de algunos Estados y con ello las amenazas a la seguridad global. ${ }^{70}$

\section{- Peligros tecnológicos}

La tecnología es una creciente fuente de progreso que puede potenciar o crear nuevas amenazas y riesgos para la seguridad.

Con la tecnología de hoy es imaginable que un grupo terrorista o un país enemigo colapsara el tráfico en el ciberespacio, paralizando, por ejemplo, el sistema financiero y parte de los servicios públicos. Por eso, la ciberseguridad, relacionada con las infraestructuras vitales para el funcionamiento de un país, se ha convertido en un ámbito clave para la seguridad de cualquier Estado. ${ }^{71}$

\section{- Ideologías radicales no democráticas}

La pérdida de peso relativo de Occidente, con su visión democrática y de supremacía del Estado de Derecho, frente al éxito económico de ciertos regímenes autoritarios que no respetan los derechos humanos, podría suponer la emergencia de modelos alternativos, atractivos para muchos habitantes de países en desarrollo.

En paralelo, existe el riesgo de que ideologías extremistas se impongan en sociedades frustradas por la inutilidad de sus Estados, de sus élites y de la comunidad internacional para dar respuesta a sus necesidades básicas. Pueden dar lugar a conflictos sociales internos y a la proliferación de actuaciones y grupos violentos. Incluso podrían expandirse en nuestra sociedad. ${ }^{72}$

${ }^{69}$ EES 2011, pág. 36-37.

${ }^{70}$ EES 2011, pág. 37.

71 EES 2011, pág. 38.

${ }^{72}$ EES 2011, pág. 38-39. 
Esteve Mora, señala que hay otros potenciadores de riesgo que las Estrategias de Seguridad han obviado, a saber:

\section{- Desindustrialización y pérdida de complejidad económica}

La pérdida de diversidad estructural de la economía española fruto de su proceso de cambio estructural, de la globalización y de la integración económica europea. La evolución estructural de España durante el siglo Xx ha pasado de otorgar prioridad al sector primario (agricultura, ganadería y pesca), posteriormente al sector secundario (industrial) y posteriormente al sector terciario (servicios), produciéndose una desindustrialización.

La desindustrialización supone un factor de riesgo añadido para la estabilidad económica por dos razones. Primero, porque plantea problemas para la balanza de pagos, dado que los servicios son por lo general menos exportables que los productos industriales. En segundo lugar, la desindustralización significa una pérdida de complejidad o diversidad económica de la producción y las exportaciones nacionales, lo que significa que, al depender la economía nacional de un número más reducido de sectores, ello la hace más vulnerable a choques negativos idisiosincrásicos que puedan afectar a alguno de ellos. ${ }^{73}$

\section{III.e. Responsabilidad respecto a las medidas a tomar en la seguridad nacional}

III.e.i. Respuesta a las amenazas a la seguridad nacional

Según quien sea el responsable de hacer frente a la amenaza, variará su respuesta, desde un punto de vista preventivo (inteligencia) o reactivo (inteligencia, policial y judicial).

\section{III.e.i.1. Inteligencia}

Según el glosario de inteligencia del Ministerio de Defensa, el concepto se define como "Producto que resulta de la evaluación, la integración, el análisis y la interpretación de la información reunida por un servicio de inteligencia» ${ }^{74}$.

${ }^{73}$ ESTEVE MORA, F.: op. cit., pág. 154.

${ }^{74}$ ESTEBAN NAVARRO, M.A. (coord..): Glosario de Inteligencia, Ministerio de Defensa, 2007, pág. 82 
Se puede diferenciar entre inteligencia como producto (información elaborada puesta al servicio del órgano decisor) o como proceso (más conocido como «ciclo de inteligencia» que consiste en una secuencia reglada que en un modelo ideal ${ }^{75}$ comprende las fases de Dirección, Obtención, Elaboración y Difusión).

Ateniéndonos al producto final de información elaborada se puede distinguir entre diferentes tipos de inteligencia: estratégica, militar, política, científica, económica, etc...

La inteligencia económica sigue los mismos parámetros expuestos supra llevados al ámbito económico. De este modo, la inteligencia económica puede definirse como una inteligencia especializada que se ocupa de la obtención y el procesamiento de la información financiera, económica y empresarial de un Estado para permitir una eficaz salvaguarda de los intereses nacionales tanto en el interior como en el exterior. ${ }^{76}$

Dentro de la inteligencia económica podemos, a su vez, especificar por materias: inteligencia básica, corporativa, competitiva (competitive intelligence), de los negocios (business intelligence), etc...

Así, de lo que expuesto en las líneas anteriores puede decirse que la función principal de la inteligencia económica es alertar de un modo temprano y certero a los Gobiernos sobre los problemas, amenazas y riesgos que acometen a nuestra economía ya sea a corto o a largo plazo.

\section{III.e.i.2. Respuesta penal}

La respuesta penal, pese a su carácter reactivo no contradice los principios de prevención que deben primar en la acción de vigilancia contra la estabilidad económica del país. Debe tenerse en cuenta que la aplicación del Derecho Penal conlleva una función de prevención general (dirigida a la colectividad para que no surjan voluntades criminales ante el temor de ser castigados con una pena) y una función de prevención especial (que incide sobre el delincuente que con la pena que ha de cumplir está sometido a la reeducación reinserción social).

75 JORDÁN ENAMORADO, J.: «Una revisión del ciclo de Inteligencia», Análisis GESI, 2/2016, Universidad de Granada, 18 de enero de 2016, pág. 1

${ }^{76}$ ESTEBAN NAVARRO, M.A. y CARVALHO, A.V.: «Inteligencia económica» en GONZÁLEZ CUSSAC, Inteligencia, Ed.Tirant lo Blanch, Valencia, 2012, pág. 48

(C) UNED. Revista de Derecho UNED, núm. 24, 2019 
Prueba de la importancia que la economía también ha tenido en el derecho sancionador y la seguridad ciudadana es la histórica desaparición del espectáculo del patíbulo por un derecho más humanitario, basado en la ocultación del castigo y que éste se redirigiese hacia unas penas más clementes estuvo basado, no sólo en las teorías de Beccaria, sino en las ideas utilitarias de Bentham y la burguesía que ostentaba el poder económico en los siglos XVIII y XIX. La pena de prisión se transformó en una forma de educar en el trabajo, cuyo modelo se basaba en el horario de las fábricas; desapareciendo la figura del condenado a prisión que permanecía recluido durante su condena a una celda en la que no hacía otra cosa que pasar el tiempo. Ahora, el preso debía contribuir en cierta manera con su trabajo y la normativización a unos horarios establecidos. Se trataba de las conocidas teorías «higienistas» que buscaban la educación de los reos adecuándolos a la vida en la sociedad productiva.

\section{III.e.ii. Operadores responsables en la seguridad nacional}

La Ley 36/2015, de Seguridad Nacional, en su artículo $4.1^{77}$ hace corresponsable a toda la ciudadanía a poder llevar a cabo los objetivos de la Seguridad Nacional. Por su parte, la EES 2011 afirma que es responsabilidad del Estado y de los agentes económicos garantizar la integridad de los mercados, la fortaleza del sistema financiero y la seguridad del comercio, y fomentar un crecimiento económico equilibrado. ${ }^{78}$ Aunque sólo la EES 2011 hace referencia expresa a qué actores son los responsables de afrontar el reto de la inestabilidad económica, no es menos cierto que todas las Estrategias vienen subtituladas con una afirmación de responsabilidad compartida o global (Una responsabilidad de todos -EES 2011-, Un proyecto compartido-ESN 2013-, Un proyecto compartido de todos y para todos -ESN 2017-). Y más allá de lo que pueda decir una estrategia de seguridad, la responsabilidad en la salvaguarda de los intereses económicos es un mandato constitucional, pues la seguridad económica está configurada como un derecho social, recogido en el art.33 de derecho a la seguridad privada, el art.38 de derecho a la libertad de empresa y los principios rectores de la política social y económica configurados en el Capítulo III del Título I, que aúnan

77 L.36/15: Artículo 4.-Política de Seguridad Nacional

1. La Política de Seguridad Nacional es una política pública en la que bajo la dirección del Presidente del Gobierno y la responsabilidad del Gobierno, participan todas las Administraciones Públicas, de acuerdo con sus respectivas competencias, y la sociedad en general, para responder a las necesidades de la Seguridad Nacional.

${ }^{78}$ EES 2011, pág. 55. 
una serie de mandatos dirigidos, en general a los poderes públicos, en orden a la promoción de las condiciones económicas, sociales y culturales de los ciudadanos ${ }^{79}$; aunque las empresas tienen una responsabilidad de primer orden en la gestión de sus intereses en materia de inteligencia económica, resulta muy discutible que sea razonable dejar que la inteligencia económica, ni en su dimensión activa, ni en su dimensión pasiva en manos puramente privadas. ${ }^{80}$

La principal característica de estos derechos económicos y sociales consiste en que no son jurídicamente exigibles y, por tanto, no pueden ser reivindicados ante los Tribunales de Justicia. La razón de ello estriba obviamente en que tales derechos dependen, para su efectivo ejercicio o realización, de la acción de los poderes públicos $\mathrm{y}$, en consecuencia, de los programas de política económica y social que los gobernantes, según su ideología, llevan a cabo dentro de las posibilidades materiales y políticas que la sociedad concede. ${ }^{81}$

Por eso es lógico que la constitución de un Estado que se autocalifica de «social» - a caballo entre el welfarestate neocapitalista y el socialismo democrático- declare una serie de obligaciones o deberes que el Estado o los poderes públicos asumen para ir realizando efectivamente los derechos de contenido económico y social que la situación actual de la sociedad capitalista y el auge de la conciencia de los ciudadanos obligan a reconocer y garantizar. ${ }^{82}$

En España, los organismos oficiales de la comunidad de inteligencia que trabajan vinculados en temas de inteligencia económica son principalmente:

\section{- El Centro Nacional de Inteligencia (CNI)}

La Ley 36/2015, de Seguridad Nacional, hace especial mención como responsable fundamental de salvaguardar la estabilidad económica y financiera a los Servicios de Inteligencia en su art.9.283; de igual manera, hay numerosas referencias en diferentes apartados de

79 SÁNZCHEZ GOYANES, E.: Constitución Española comentada, (21. a edición), Ed.Paraninfo, Madrid, 1998, pág. 104.

80 MARTÍN BARBERO, I.: "Inteligencia económica: tan lejos, tan cerca», pág. 118

${ }^{81}$ GONZÁleZ CASANOVA, J.A.: Teoría del Estado y Derecho Constitucional, (3. ${ }^{a}$ edición), Ed.Vicens Vives, S.A., Barcelona, 1984, pág. 467.

82 Ibidem., pág. 467.

${ }^{83}$ L.36/15: Artículo 9.-Componentes fundamentales de la Seguridad Nacional.

2. Los Servicios de Inteligencia e Información del Estado, de acuerdo con el ámbito de sus competencias, apoyarán permanentemente al Sistema de Seguridad Nacional, proporcionando elementos de juicio, información, análisis, estudios y propuestas necesarios para prevenir y detectar los riesgos y amenazas y contribuir a su neutralización.

(C) UNED. Revista de Derecho UNED, núm. 24, 2019 
la redacción de las Estrategias de Seguridad. La Ley 11/2002 de 6 de mayo de 2002 reguladora del Centro Nacional de Inteligencia también está en esta línea cuando en su artículo $4 a$ reza que una de las principales funciones del CNI será la de: «Obtener, evaluar e interpretar información y difundir la inteligencia necesaria para proteger y promover los intereses políticos, económicos, industriales, comerciales y estratégicos de España, pudiendo actuar dentro o fuera del territorio nacional». El citado artículo 4 permitirá que La Casa (nombre con el que también se conoce al CNI), participe en operaciones empresariales de gran envergadura ${ }^{84}$

En la realización de su labor, los servicios de inteligencia tienen la competencia de sensibilizar a las empresas sobre riesgos y amenazas e informar sobre medidas de prevención; realizar análisis de tipo macro sobre la economía y las empresas de países de interés; proteger los intereses económicos en el mercado interno y promocionarlos en el exterior; y crear y desarrollar una comunidad y una cultura de inteligencia económica dirigida a involucrar a las empresas en esta actividad y estimularlas a practicar de modo sistemático la inteligencia competitiva. De este modo, la suma de las acciones y la coordinación de esfuerzos del Estado y de las empresas en el campo de la inteligencia económica favorecen la seguridad económica de un país. ${ }^{85}$

Dentro de la estructura del CNI será la Subdirección de Inteligencia Exterior y la Subdirección de Contrainteligencia las que deban hacerse cargo de la inteligencia económica.

- Servicio Ejecutivo de Prevención del Blanqueo de Capitales (SEP$B L A C)$

El SEPBLAC es un órgano adscrito al Banco de España, que se configura como la Unidad de Inteligencia Financiera que recomiendan el Grupo Egmont y la Recomendación 26 del GAFI. Como tal Unidad de Inteligencia tiene doble dependencia funcional de la Secretaría de Estado de Economía (en su investigación del blanqueo de capitales) y de la Secretaría de Estado de Seguridad (en la investigación de la financiación del terrorismo). El personal que integra el SEPBLAC pertenece a las Fuerzas y Cuerpos de Seguridad y al Ministerio de Hacienda.

${ }^{84}$ GONZÁLEZ CUSSAC, J.L.y LARRIBA HINOJAR, B.: Ob.cit., pág. 19.

85 ESTEBAN NAVARRO, M.A. y Andréa V. CARVALHO, A.V.: Ob.cit., pág. 4849. 
El SEPBLAC dará cuenta de cuantas investigaciones hayan realizado a la Agencia Tributaria, Fiscalía y Juzgados. Asimismo, será el órgano que reciba todas las informaciones sospechosas detectadas por los sujetos obligados por la Ley de prevención del blanqueo a guardar las medidas de diligencia debida. Una vez que el SEPBLAC recibe las comunicaciones de los sujetos obligados, procede a analizarlas. Después de evaluar su gravedad y legitimidad, da traslado de las mismas a la policía, a los tribunales y a otras autoridades ${ }^{86}, \sin$ que sirva de elemento probatorio directo, puesto que se trata de comunicaciones sospechosas, y no de evidencias indiscutibles ${ }^{87}$.

\section{- Comunidad de inteligencia ampliada}

También en el caso de la inteligencia económica es necesario hablar, al igual de lo que ocurre en otros países, de la necesidad de contar de una comunidad de inteligencia ampliada, donde participan principalmente actores estatales tales como el Instituto de Comercio Exterior, las oficinas económicas y comerciales en el exterior y no estatales como los departamentos de estrategia y desarrollo de negocio de las grandes empresas multinacionales españolas y la comunidad financiera, destacando el papel como reservas de inteligencia de los no pocos ciudadanos españoles que tienen puestos de responsabilidad en los centros financieros mundiales, siendo el papel de las universidades más reducido en este ámbito. ${ }^{88}$ En este sentido, podemos celebrar la reciente creación (octubre de 2018) del Observatorio MESÍAS de Inteligencia Económica y Competitiva, desarrollado por MESIAS, el sistema de inteligencia de Marca España al servicio de España Global (antigua Marca España), y en colaboración con la Cátedra de Servicios de Inteligencia y Sistemas Democráticos. Este Observatorio nace con la vocación de monitorizar y analizar el estado y evolución de la Inteligencia Económica y Competitiva en España, como pilar esencial de la Estrategia de Seguridad Nacional, y proponer recomendaciones estratégicas que permitan su refuerzo y fortalecimiento de cara a la competencia en un mundo global. ${ }^{89}$

${ }^{86}$ BLANCO CORDERO, I.: «Eficacia del sistema de prevención del blanqueo de capitales. Estudio del cumplimiento normativo (compliance) desde una perspectiva criminológica», Eguizkilore, número 23, San Sebastián, diciembre 2009, pág. 130.

${ }^{87}$ MARTÍN VELASCO, L.: «La investigación policial en el blanqueo de capitales», en GONZÁLEZ CUSSAC, J.L. (Dir.) y otros: Financiación del terrorismo, blanqueo de capitales y secreto bancario: un análisis crítico, Ed.Tirant lo Blanch, Valencia, 2009, pág. pág. 227.

${ }^{88}$ FERRER RODRÍGUEZ, J.: Ob.cit., pág. 6

89 REDACCIÓN: «Presentado el Observatorio MESIAS de Inteligencia Económica y Competitiva», noticia publicada en la página web https://www.uspceu.com/ prensa/NoticiaCompleta.aspx?q1=5802\&q2=NOT [consultado el 24/10/2018].

(C) UNED. Revista de Derecho UNED, núm. 24, 2019 


\section{— Juzgados y Tribunales}

Es la parte más visible y decisoria de la Administración de Justicia. Está integrada por Jueces y Magistrados, que administran la Justicia en nombre del Rey (art.117 CE y 1 L.O.5/85 del Poder Judicial).

Respecto a materia económica, serán los jueces del orden civil (en su vertiente de derecho mercantil) y del orden penal los encargados de enjuiciar las causas de índole económica que se les presenten. Asimismo, debe tenerse en cuenta que un Magistrado del Tribunal Supremo controlará judicialmente las actuaciones del CNI que afecten a los derechos recogidos en el art. 18.2 y 3 de la Constitución, concediendo las autorizaciones previas necesarias para el cumplimiento de las funciones que tiene asignadas tal como establecen el artículo 12 de la Ley 11/2002 y el artículo único de la Ley Orgánica 2/2002.

\section{- Ministerio Fiscal}

El Ministerio Fiscal forma parte de la Administración de Justicia. Sin perjuicio de las funciones encomendadas a otros órganos, tiene por misión promover la acción de la justicia en defensa de la legalidad, de los derechos de los ciudadanos y del interés público tutelado por la ley, de oficio o a petición de los interesados, así como velar por la independencia de los Tribunales y procurar ante éstos la satisfacción del interés social (art.124.1 C.E. y 541 L.O.5/85 del Poder Judicial).

La Fiscalía tiende a organizarse en función a áreas de especialización; en el caso que nos ocupa, la Fiscalía Especial en materia de delitos económicos, que coordina la actividad de las distintas Fiscalías Territoriales en la materia de delincuencia socioeconómica, excepto la que es competencia de la Fiscalía Anticorrupción.

\section{- Fuerzas y Cuerpos de Seguridad del Estado}

Las FFCCSE, integradas en el Ministerio de Interior, tienen como misión proteger el libre ejercicio de los derechos y libertades y garantizar la seguridad ciudadana (art.104.1 CE y 11 L.O.2/86 de Fuerzas y Cuerpos de Seguridad), que en sus funciones de policía judicial específica atenderá a las siguientes funciones (art.549 LO. 5/85 del Poder Judicial):

a) La averiguación acerca de los responsables y circunstancias de los hechos delictivos y la detención de los primeros, dando 
cuenta seguidamente a la autoridad judicial y fiscal, conforme a lo dispuesto en las leyes.

b) El auxilio a la autoridad judicial y fiscal en cuantas actuaciones deba realizar fuera de su sede y requieran la presencia policial.

c) La realización material de las actuaciones que exijan el ejercicio de la coerción y ordenare la autoridad judicial o fiscal.

d) La garantía del cumplimiento de las órdenes y resoluciones de la autoridad judicial o fiscal.

e) Cualesquiera otras de la misma naturaleza en que sea necesaria su cooperación o auxilio y lo ordenare la autoridad judicial o fiscal.

Las Fuerzas y Cuerpos de Seguridad, consecuentemente con la especialización delictiva, han ido configurando en sus estructuras internas grupos especializados con formación adecuada para la investigación de delitos económicos, como son los casos de la Jefatura de Policía Judicial y de Información de Policía Nacional y Guardia Civil.

\section{CONCLUSIONES}

La actualidad ha hecho realidad la máxima de que es más poderosa la pluma que la espada. Se puede convenir que en el actual momento geopolítico influyen más las medidas diplomáticas y políticas con sus estrategias psicológicas que la fuerza militar y/o material; de igual manera que se puede hablar del superior poder destructivo en la sensación de inseguridad que supone la amenaza de los delincuentes de cuello blanco sobre los delincuentes de baja estofa.

La economía impregna casi todos los ámbitos de nuestra vida, de manera que el resto de amenazas a la seguridad nacional también influyen tangencial, o directamente sobre la economía y ésta sobre la seguridad y bienestar de los ciudadanos. Y a pesar de ser uno de los asuntos más analizados por los especialistas, ya sea por economistas, sociólogos, politólogos, juristas, etc..., sus pronósticos distan mucho de ser certeros, como puede observarse, y padecerse con la crisis económica y financiera que va camino de cumplir una década.

Aunque la economía debería atenerse a la ciencia numérica, sus operadores son personas que actúan condicionados por sus inclinaciones políticas, intereses particulares, sensaciones, etc... La inteli- 
gencia económica y financiera debería basarse en buena parte en un asentado conocimiento académico económico e histórico - toda vez que la economía se mueve de forma cíclica.

Para hacer frente a las amenazas a la inestabilidad económica y financiera se puede optar por diferentes puntos vista, a saber:

- dimensión preventiva y prospectiva: es el campo propio de la inteligencia, que a través del conocimiento de nuestro entorno y de nuestros posibles adversarios anticiparemos los posibles movimientos nocivos a nuestros intereses. La inteligencia deberá dotar al órgano decisor de un catálogo de medidas entre las que pueden estar las de aumentar los entornos de seguridad de secretos industriales, de contrainteligencia, diplomáticas, etc...

- dimensión reactiva: derivada de la aplicación de las resoluciones judiciales motivadas en el incumplimiento de la ley (penal y civil-mercantil). La aplicación de la ley penal no deja de ser una medida preventiva, pues con sus penas persigue una prevención general (de escarmiento en penado, que es tomado como ejemplo por el resto de la ciudadanía para huir de las conductas ilegales), pero también como prevención especial (buscando la reinserción y resocialización para no volver a cometer los mismos hechos).

Cabe deducir por lo expuesto, que es la dimensión preventiva la más acertada para mitigar los efectos adversos de un ataque a nuestra estabilidad, pues a pesar de la visibilidad y la contundencia que puede otorgar un escenario judicial, el mundo de la economía y de la seguridad en particular es un entorno abstracto y de un alto componente subjetivo, por lo que siguiendo la máxima latina quod non est in actis non est in mundo, los tribunales puedan no llegar a determinar la existencia de pruebas contundentes para condenar el ataque; asimismo, si a la evanescencia de pruebas añadimos que estos ataques pueden provenir de otros países podrían entrar en juego otras jurisdicciones con la consiguiente confusión jurídica.

Ahora bien, admitiendo que la Inteligencia es la herramienta más adecuada para hacer frente a las amenazas y desafíos a la Seguridad Nacional en general, y a la inestabilidad económica y financiera en particular, deben tomarse ciertas reservas respecto a esta disciplina. Cuando se habla de Inteligencia se hace una ciencia que ha sido calificada de ciencia postmoderna, es decir, de un conocimiento que siguiendo las pautas del método científico obvia algunos de sus pasos 
debido al entorno de emergencia, premura en las conclusiones, y a que se aleja del concepto de ciencia numérica que caracteriza a las ciencias exactas en contraposición con las ciencias sociales.

Si bien la información es poder, en el ámbito económico está información debería ser vital, y en ello se basa la inteligencia económica, estratégica y competitiva. No obstante, es opinión del autor que no debería ponerse una fe ciega en las conclusiones plasmadas en los documentos de inteligencia, toda vez que éstos en sus previsiones realizarán un acto de prospectiva que avancen las soluciones a futuros problemas, y la realidad hasta el momento ha demostrado que ningún país de la órbita occidental ha eludido las crisis económicas que se han venido dando a lo largo de la historia.

Preparación, sí, pero relativizar las conclusiones que se aporten en la Inteligencia, apostando — quizás en su sentimiento pesimistaque a lo más que se puede llegar es a minimizar las consecuencias de una crisis, un ataque o una inacertada política. 